$16^{\text {th }}$ International Conference on

AEROSPACE SCIENCES \& AVIATION TECHNOLOGY,

ASAT - 16 - May 26 - 28, 2015, E-Mail: asat@ mtc.edu.eg

Military Technical College, Kobry Elkobbah, Cairo, Egypt

Tel : +(202) $24025292-24036138$, Fax: +(202) 22621908

\title{
Behavior of Reinforced Concrete Slab with Aluminum Foam Panels Subjected to Blast Loadings M. M. MAHMOUD ${ }^{1}$, H. M. FARAG ${ }^{2}$ and S. Y. MAHFOUZ ${ }^{3}$
}

\begin{abstract}
The main objective of the current research work is to investigate the dynamic response of reinforced concrete $(\mathrm{RC})$ slab protected by a composed layer of aluminum foam panel and steel plate. The RC slab and the protection layer were subjected to blast loading. A parametric study was conducted in which a series of numerical simulations of protected and unprotected RC slabs was performed using hydro-code software (i.e. AUTODYN 3D). A set of published experimental tests was used to validate the numerical models proposed. The models were simulated as protected and unprotected RC slabs subjected to different blast loads. In the numerical simulations, the dynamic behavior of reinforced concrete and aluminum foam materials as porous materials were defined utilizing different Equations of State (EOS) and strength models. Time-dependent results of the response of the RC slabs subjected to the blast loads were obtained. The computed results were then utilized to study the efficiency of aluminum foam and steel plate layer to maintain the maximum deflection of the RC slab within its elastic limit.
\end{abstract}

Keywords: Concrete slabs, Aluminum Foam, blast loadings.

\section{Introduction}

The use of explosives to attack important governmental buildings has been a feature of campaigns by terrorist organizations around the world. Explosion produces extreme pressure loads to damage buildings. The pressure load is based on the standoff distance and explosive charge weight [1]. This load may result in different damage scenarios to a building. To avoid this damage, various techniques have been developed to protect buildings against the destructive effect of blast loading with various degrees of success. Researches directed their study to investigate the effect of using different composite materials as protecting layers.

${ }^{1}$ Graduate Student, Civil Eng. Dept., Military Technical College, Egyptian Armed Forces, Cairo, Egypt.

${ }^{2}$ Dr. Civil Eng. Dept., Military Technical College, Egyptian Armed Forces, Cairo, Egypt.

${ }^{3}$ Assoc. Prof., Construction and building Eng. Dept., Arab Academy for Science, Technology, and Maritime Transport, Cairo, Egypt. 
These materials comprise polyuria, E-glass vinyl ester, glass fiber reinforced polymer, steel synthetic, long carbon fibers, and ultra-high performance fiber reinforced concrete [2-5].

Aluminum foam is a lightweight material with excellent plastic strain energy. The aluminum foam material behaves as a perfect-plastic material. Moreover, aluminum foam can absorb high blast energy at a nearly constant stress level because of its long plastic plateau in compression [6]. The typical behavior of aluminum foam was illustrated by Hanssen (2002)[7] and Chengqing and Hamid (2011) [8].The characteristics of aluminum foam attract few researches to use composite sandwich panels having aluminum cores as sacrificial layers. Among them, (Chi 2010) [9] experimentally investigated the influence of core height and face plate thickness on the response of honeycomb sandwich panels subjected to blast loading. It was found that increasing the core thickness delayed the onset of core densification and decreased the back plate deflection. Also increasing the plate thickness decreased the back plate deflection. Full scale explosive tests on protected and unprotected concrete slabs were conducted by Schenker et al.(2008) [10] where several layers of aluminum foams were studied. The authors illustrated and verified the effectiveness of the using aluminum foam for reducing the slab response.

Based on the previous studies, it can be concluded that the blast response of RC slab protected using a layer of aluminum foam and steel plate remains unclear. In the present study, a numerical parametric study was conducted using hydro-code software (i.e. AUTODYN 3D) where the slab, aluminum foam and steel plate layer, surrounding air, and explosive charge were modeled. The displacement time history for each case study was obtained. Then, the maximum displacement for each case study was computed. These displacements were then utilized to study the efficiency of using a layer of aluminum foam and steel plate to maintain the deflection of the RC slab within its elastic limit calculated using approximated design method [1].

\section{Material models}

In the present study, equations of state and strength models are used to describe the materials in the numerical simulation. For air, the ideal gas equation of state (EOS) [11] is :

$P=(\gamma-1) \rho e+P_{\text {shift }}$

Where, $P$ is the pressure. The adiabatic constant is $\gamma$ and equals 1.4 for air behaving like an ideal gas. The air density is $\rho$ and $e$ is a specific internal energy. A small pressure $\left(P_{\text {shift }}\right)$ is defined to give a zero staring pressure to avoid complication in problems with multiple materials where initial small pressures in the gas would generate small unwanted velocities. Table 1 presents the material properties of air used in AUTODYN.

The Jones-Wilkins-Lee (JWL) equation of state is used to describe the explosive, which is in the form:

$$
P=A\left(1-\frac{\omega}{R_{1} V}\right) e^{R_{1} V}+B\left(1-\frac{\omega}{R_{2} V}\right) e^{-R_{2} V}+\frac{\omega E}{V}
$$

Where $A, B, R_{1}, R_{2}, \omega$ are empirically derived constants which depend on the type of explosives, $\mathrm{V}$ is the relative volume or the expansion of the explosive product, and $E$ is the detonation energy per initial unit volume. These parameters were derived from Dobratz and Crawford [12]. The material properties used of air and TNT are given in Table 1.

Herrman (1969) [13] proposed a porous equation of state for concrete and this considered the concrete inhomogeneity and porosity. Equation 3 describes the behavior of fully compacted material while the porous material is scaled using the porosity $(\alpha)$. Thus for the fully compacted material the pressure $(P)$ equals $P_{l o c k}$ and the porosity $\alpha$ equals 1 and the pressure was calculated using the solid polynomial equation as presented in equation (3). 
Table (1) Physical Data for Air and TNT

\begin{tabular}{|c|c|c|c|}
\hline Item & Air & TNT & TNT (Ideal) \\
\hline \multirow{5}{*}{ Equation of state } & Ideal Gas & JWL & Ideal Gas \\
\hline & $\gamma=1.4$ & \multirow{4}{*}{$\begin{array}{c}\text { Standard } \\
\text { library data }\end{array}$} & $\gamma=1.35$ \\
\hline & $\rho=1.225 \times 10^{-3} \mathrm{~g} / \mathrm{cm}^{3}$ & & $\rho=10^{-4} \mathrm{~g} / \mathrm{cm}^{3}$ \\
\hline & Ref. Energy $=0 \mu \mathrm{J}$ & & Ref. Energy $=0 \mu \mathrm{J}$ \\
\hline & Press. Shift $=0 \mathrm{kPa}$ & & Press. Shift $=0 \mathrm{kPa}$ \\
\hline \multirow[b]{2}{*}{ Initial Conditions } & $\rho=1.225 \times 10^{-3} \mathrm{~g} / \mathrm{cm}^{3}$ & \multirow[b]{2}{*}{ Default } & From detonation \\
\hline & $\begin{array}{l}\text { Ref. Energy }=2.068 \text { E5 } \\
\mu \mathrm{J} / \mathrm{mg}\end{array}$ & & Model/remap data \\
\hline
\end{tabular}

For pressure greater than $P_{\text {crush }}$ and less than $P_{\text {lock }}$, the pressure was scaled using equation 4.

$P=A_{1} \mu+A_{2} \mu^{2}+A_{3} \mu^{3}+\left(B_{0} \mu+B_{1} \mu\right) \rho_{0} e$ with $\quad \mu=\frac{\rho}{\rho_{0}}-1$

$P=f(\rho, e) \stackrel{\text { porus }}{\longrightarrow} P=f(\rho \alpha, e)$ with $\alpha=1+\left(\alpha_{\text {init }}-1\right)\left[\frac{P_{\text {lock }}-P}{P_{\text {lock }}-P_{\text {crush }}}\right]^{n}$

The data that defines the concrete material (conc-35MPA) material in the hydro-code [11]was chosen from the library and modified to match those used in the experimental work carried by Chengqing and Hamid (2013) [14].

P-Alpha equation of state and polynomial solid EOS with Riedel, Hiermaier and Thoma (RHT) [15] Concrete strength model were applied. Reference density of concrete equals 2.75 $\mathrm{gm} / \mathrm{cm}^{3}$, Compressive strength equals $3.2 \mathrm{e} 4 \mathrm{kPa}$ and Shear modulus equals $1.67 \mathrm{e} 7 \mathrm{kPa}$.

The data that defines the steel reinforcement (Steel 1006) material in the hydro-code [11] was chosen from the library and modified. The linear equation of state and strength model (Johnson and Cook 1983)[16]were applied. The yield stress of steel was assumed $3.5 \mathrm{e} 5 \mathrm{kPa}$ and its shear modulus was $8.18 \mathrm{e} 7 \mathrm{kPa}$

The dynamic behavior of aluminum foam material as a porous material was described using the approach proposed by Kipp (1999)[17]where the equation of state P- $\alpha$ compaction model together with the von Mises yield strength were used. The von Mises yield criterion describes the material elastic limit and its inability to support large shear stresses. Material failure occured when the material was not able to withstand tensile stresses exceeding the material's local tensile strength. The hydrodynamic tensile model was used for simulation, and the model requires a specified constant hydrodynamic tensile limit to determine failure occurrence. The physical data of aluminum foam inserted in AUTODYN were porous density equals $0.5 \mathrm{gm} / \mathrm{cm}^{3}$, initial compaction pressure set7 MPa, solid compaction pressure was 133 $\mathrm{MPa}$, compaction exponent considered 1.4, Shear Modulus was $1.88 \mathrm{GPa}$, Yield Stress proposed $7 \mathrm{MPa}$, and the Hydro Tensile limit was $-2 \mathrm{GPa}$.

\section{Validation Analysis}

The current validation model was conducted using two case studies (i.e. protected and unprotected slabs) experimentally performed by Zhu and chai (2009) [18]. The dimensions of each slab were $2000 \mathrm{~mm}$ long and $400 \mathrm{~mm}$ width, and $100 \mathrm{~mm}$ thickness. The slabs were designed with both tension and compression reinforcement using $12 \mathrm{~mm}$ diameter steel mesh and $15 \mathrm{~mm}$ concrete cover. Steel bars were spaced at $326 \mathrm{~mm}$ centers in the major bending plane and $89.5 \mathrm{~mm}$ in the minor plane as shown in Fig. (1). Concrete compressive strength was 3.2e4 kPa with Young's modulus of $26 \mathrm{GPa}$. Steel bar yield strength was $500 \mathrm{MPa}$ and its Young's modulus was $200 \mathrm{GPa}$. Aluminum foam layer of $75 \mathrm{~mm}$ thickness was used to cover the surfaces of three reinforced concrete slabs. The standoff distance is $1500 \mathrm{~mm}$. The 
TNT charge weight was $8.2 \mathrm{Kg}$. Zhu and chai [18] measured the deflection of two points, shown in Fig. 1-a. Also, Chengqing and Hamid (2013)[14] proposed an analytical technique and used these tests data for validation.

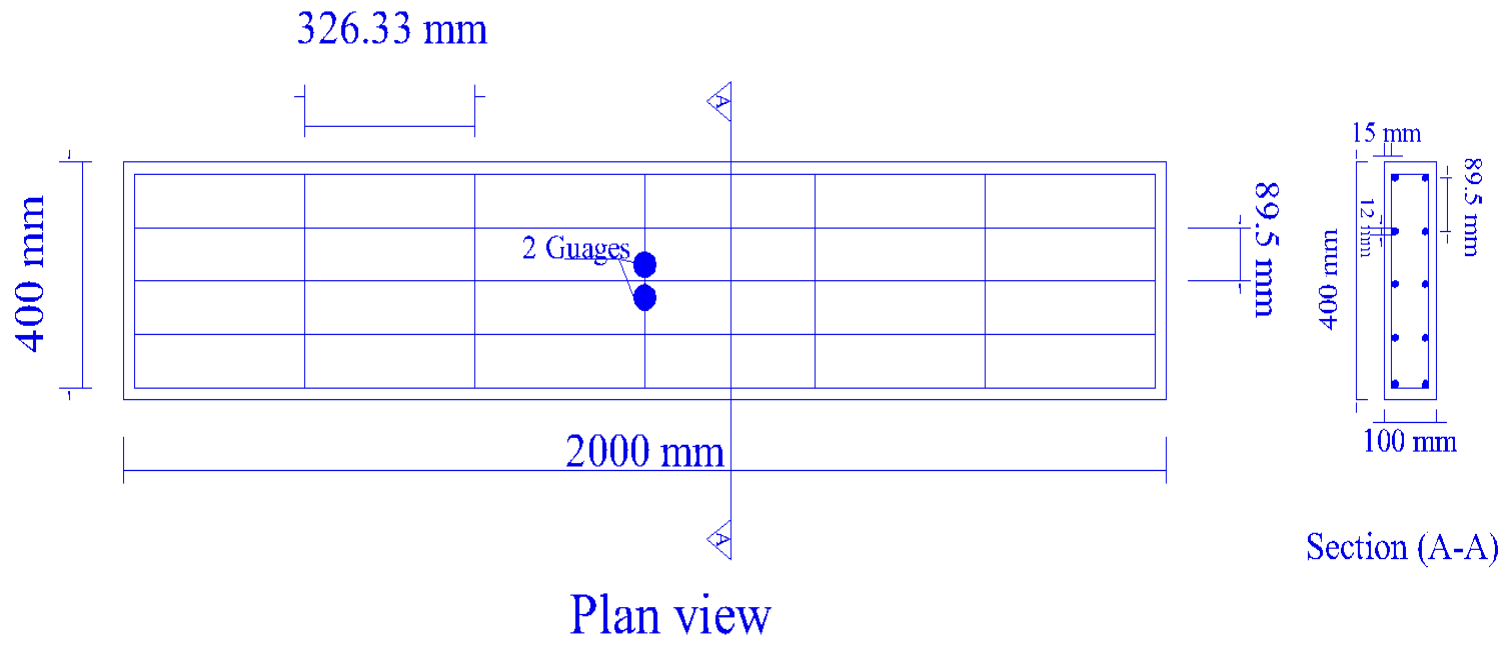

Fig. (1) The dimensions of tested slab

In the current research, two-steps approach was performed in order to save computational time. The first step comprises creation of a 2D model of explosion in air. The second step included importing of the remapped file into a 3D model.

The lagrangian process was used to describe the material movement of the concrete slab and the aluminum foam Air domain was modeled as Euler ideal gas in domain size of $(3500 \times$ $3000 \times 3000) \mathrm{mm}$. Reinforced steel bars were modeled as beam element. Fig. 2-a shows the unprotected slab model, steel mesh reinforcement and location of the two points selected. Fig. 2-b illustrates the model setup.

The dynamic analysis for the two case studies was performed and the results were extracted from AUTODYN. The deflection time histories of the unprotected and protected slabs were depicted as shown in Figs. 3 and 4 respectively. It can be observed that the trend of deflection-time history of both cases are in a good agreement with those presented by Chengqing and Hamid (2013) [14] and Zhu and chai (2009) [18].

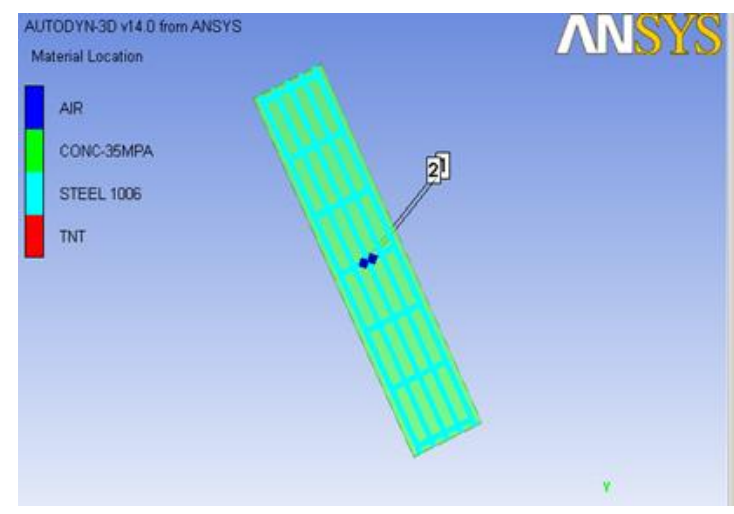

(a)

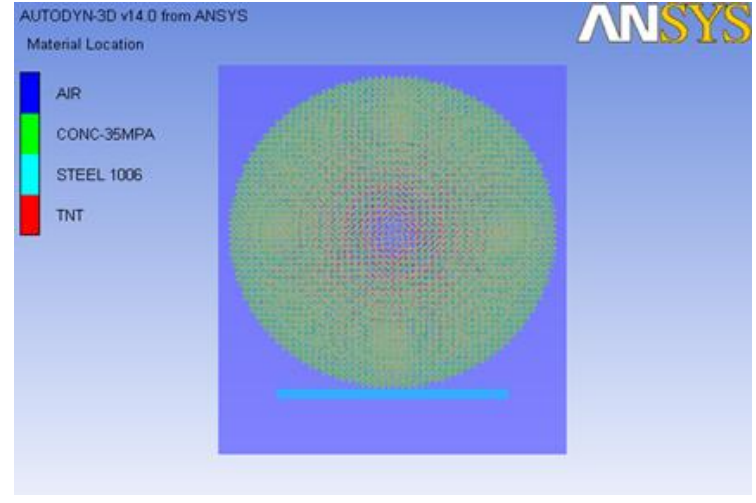

(b)

Fig. (2) AUTODYN 3-D unprotected slab model 


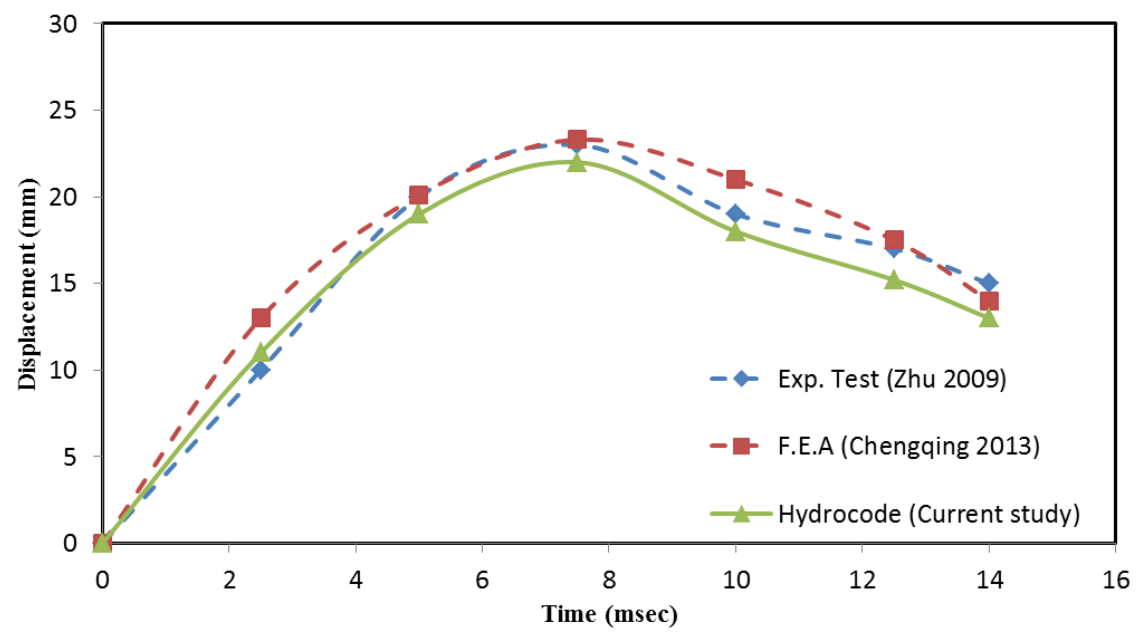

Fig. (3) Displacement-time history for unprotected slab

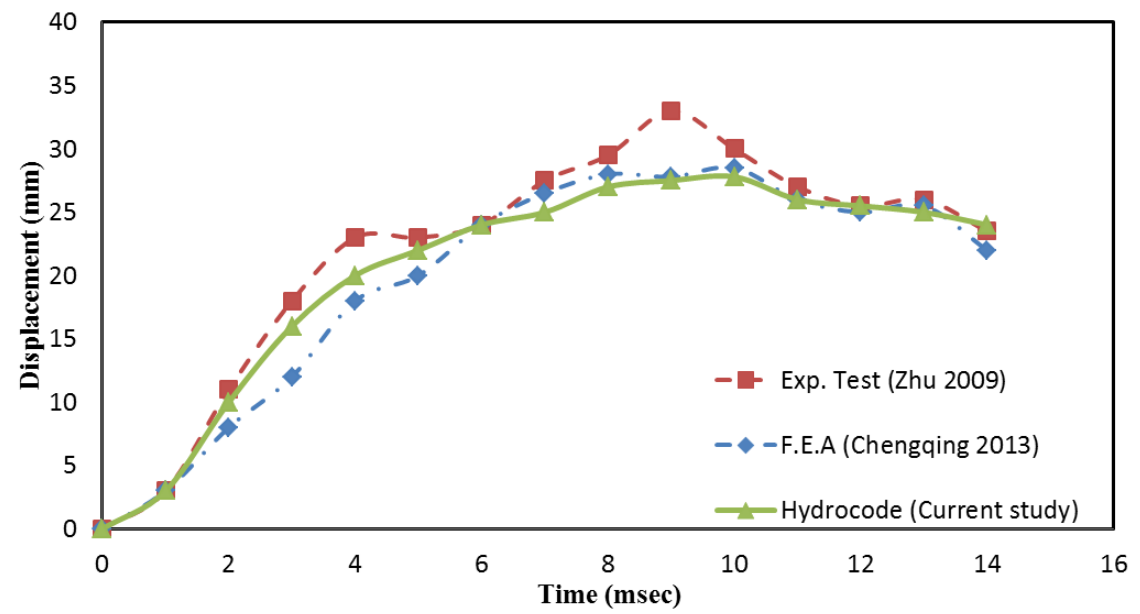

Fig. (4) Displacement-time history for unprotected slab

\section{Parametric study}

The computational models were built to investigate the effect of using protecting layer composed of aluminum foam and steel plate on the response of reinforced concrete slabs. Two RC slabs (A and B) were considered. The dimensions of RC slabs (A and B) were $(4000 \times 3000 \times 200 \mathrm{~mm})$ and $(4000 \times 3000 \times 150 \mathrm{~mm})$ respectively. The slabs and protection layer were totally clamped from their sides. A parametric study was conducted for each slab. Each slab, the parameters were thickness of aluminum foam, scaled distance, and thickness steel plate.

The two slabs were firstly designed using approximate design method utilizing (TM5UFC)[1]. The maximum pressure loads were 269 and $202 \mathrm{kPa}$ for slabs A and B respectively. These values were calculated so that the maximum deflection for each slab equal to its elastic deflection. Results showed that the maximum elastic deflections were 4.3 and $5.2 \mathrm{~mm}$ for slab $\mathrm{A}$ and $\mathrm{B}$ respectively.

Utilizing AUTODYN, the RC slab and aluminum foam were modeled as described before. The steel plate was modeled using shell element. Air domain was modeled as Euler ideal gas in domain size of $(6500 \times 6000 \times 5000) \mathrm{mm}$. Two moving gauges were added to the reinforced concrete slab at the mid-span of the slab. Fig. 5-a shows the protected slab model using a panel composed of steel plate and aluminum foam and explosion in air medium. Fig. 5 -b illustrates the steel mesh reinforcement and locations of the gauges. The stand-off distance was 4.0 meters. The TNT charge weights were 3, 5, 9, 10 and $15 \mathrm{Kg}$. These values produced peak over pressures and impulses as given in Table 2. Utilizing TM5-UFC, peak over pressures and impulses were calculated and these were obtained typical to those computed using AUTODYN. The pressure time histories are presented in Fig. 6. 
As shown in Table 2, the parameters investigated were thickness of reinforce concrete slab, aluminum foam, scaled distance, and thickness steel plate. For each case study, the displacement time history was obtained. Then, the maximum displacements were extracted. These displacements were then utilized to study the efficiency of using a layer of aluminum foam and steel plate to maintain the deflection of the RC slab within its elastic limit as shown in Table 3.

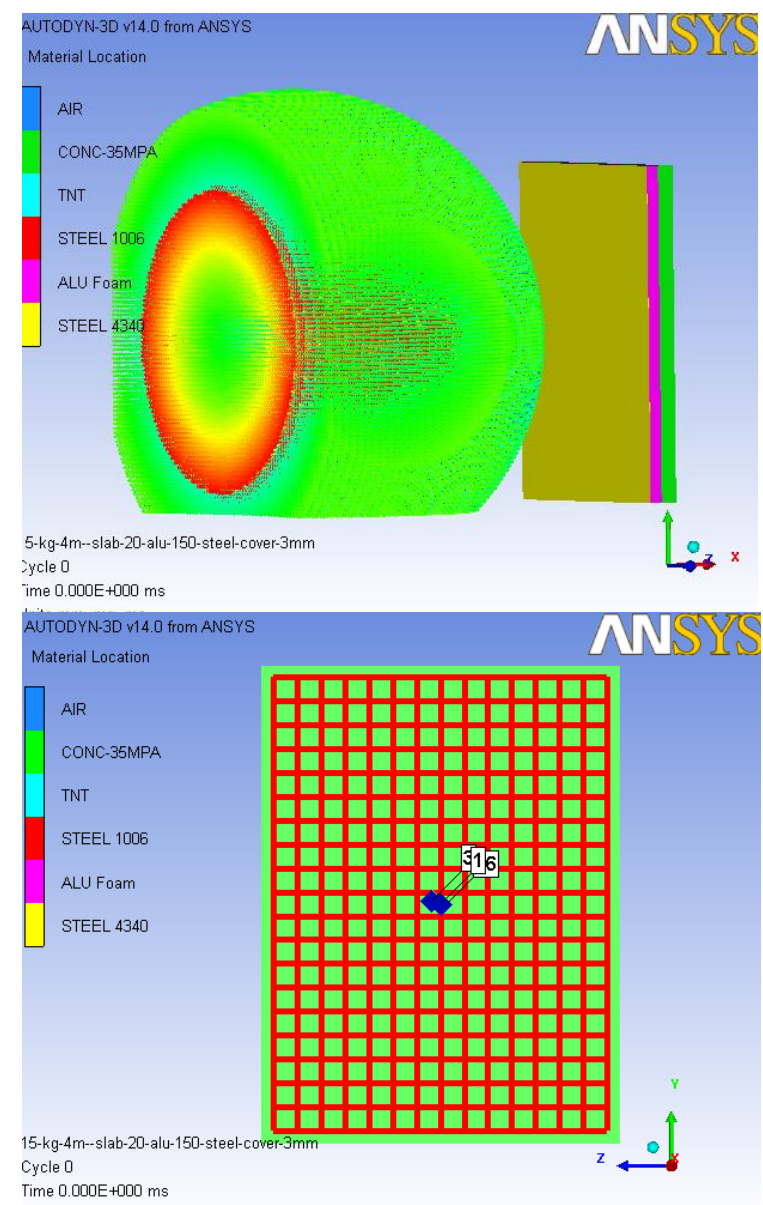

(a)

Fig. (5) AUTODYN 3D model of the current study.

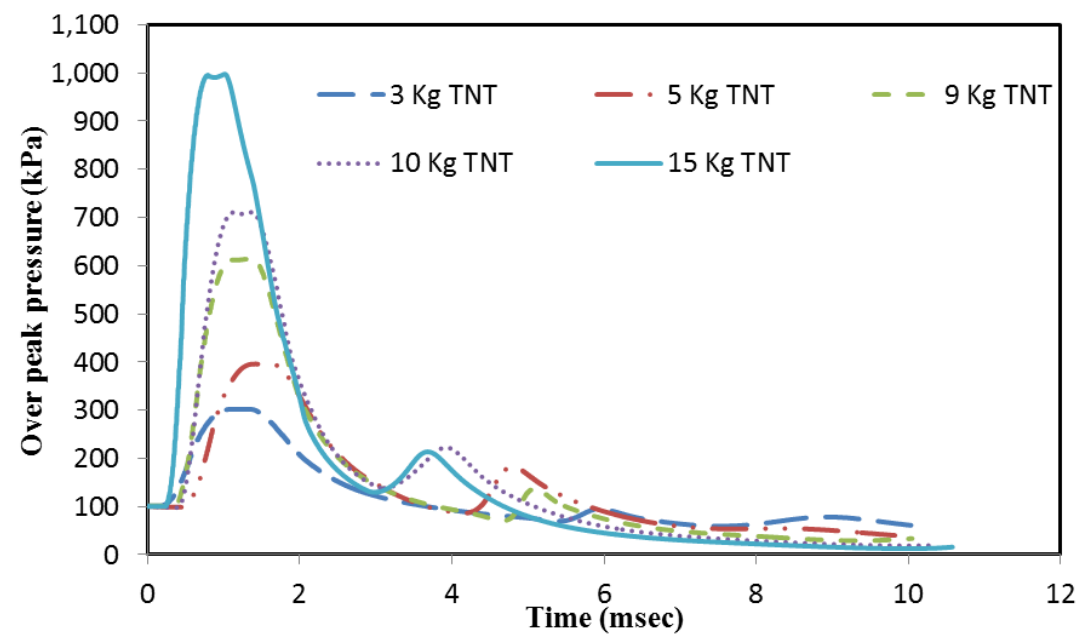

Fig. (6) Pressure-time histories for different charges of TNT at stand-off distance $4 \mathrm{~m}$ 
Table 2. The parameters of explosive charges.

\begin{tabular}{ccccc}
\hline $\begin{array}{c}\text { Charge weight } \\
(\mathbf{k g} \text { TNT })\end{array}$ & $\begin{array}{c}\text { Stand-off distance } \\
(\mathbf{m})\end{array}$ & $\begin{array}{c}\text { Scaled distance } \\
\left(\mathbf{m} / \mathbf{k g}^{\mathbf{1 / 3}}\right)\end{array}$ & $\begin{array}{c}\text { Peak over pressure } \\
(\mathbf{K P a})\end{array}$ & $\begin{array}{c}\text { Impulse } \\
(\mathbf{K P a}) \mathbf{m s})\end{array}$ \\
\hline $\mathbf{3}$ & 4 & 2.77 & 202 & 344 \\
$\mathbf{5}$ & 4 & 2.34 & 269 & 498 \\
$\mathbf{9}$ & 4 & 1.92 & 515 & 1004 \\
$\mathbf{1 0}$ & 4 & 1.86 & 607 & 1214 \\
$\mathbf{1 5}$ & 4 & 1.62 & 890 & 1825 \\
\hline
\end{tabular}

\section{Discussion of Results}

From Table 3, it can be seen that the ratio between the maximum slab deflection to the maximum elastic slab deflection $(\mu)$ increased by increasing the charge weight when considering the same protection layer for a certain slab. Adding aluminum foam panel of thickness $200 \mathrm{~mm}$ for to protect slab B (i.e model 11) has a significant effect in energy absorption as shown in Fig. 7.

For slab A, aluminum foam layer of thickness less than $200 \mathrm{~mm}$ did not maintain the maximum deflection to its elastic deflection limit when the scaled distance equals 1.86 . The use of a layer composed of either aluminum foam of $200 \mathrm{~mm}$ thickness or aluminum foam of $150 \mathrm{~mm}$ thickness and steel plate of $3 \mathrm{~mm}$ thickness reduces the maximum deflection to a value less than its elastic deflection limit. Considering scaled distance equals 1.62, the maximum deflection of slab A approximately reduced to its elastic deflection limit when the slab is protected utilizing a layer composed of either aluminum foam of $250 \mathrm{~mm}$ thickness or aluminum foam of $200 \mathrm{~mm}$ thickness and steel plate of $3 \mathrm{~mm}$ thickness.

Having scaled distance of 1.92 for slab B, the maximum slab deflection was maintained to its elastic limit when the protection layer was either aluminum foam of $200 \mathrm{~mm}$ or aluminum foam of $150 \mathrm{~mm}$ and steel plate of $3 \mathrm{~mm}$ thickness.

The crack patterns of slabs were also monitored during the numerical simulation. The crack patterns of slabs for the cases studied at which the maximum slab deflection was maintained within its elastic limit are shown in Figs. (8-10). In these figures, it can be shown that there is no damage occurred and the cracks are minimized and located at the lower and upper edges of the slabs investigated. The displacement time histories for the same cases study mentioned later were displayed as shown in Figs. (11-13).

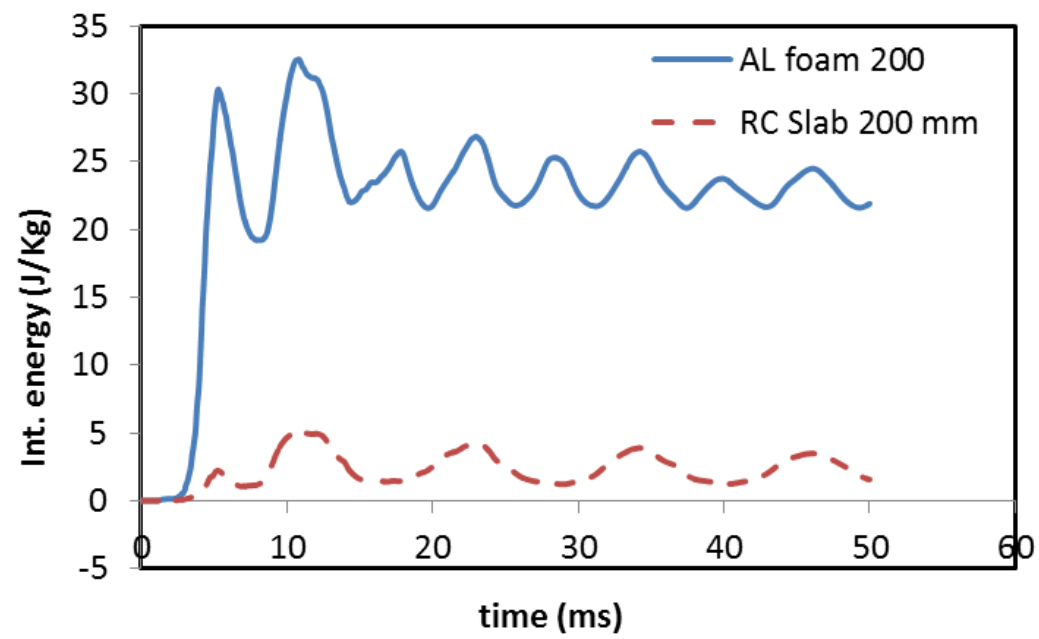

Fig. (7) Int. energy-time history for model 11 


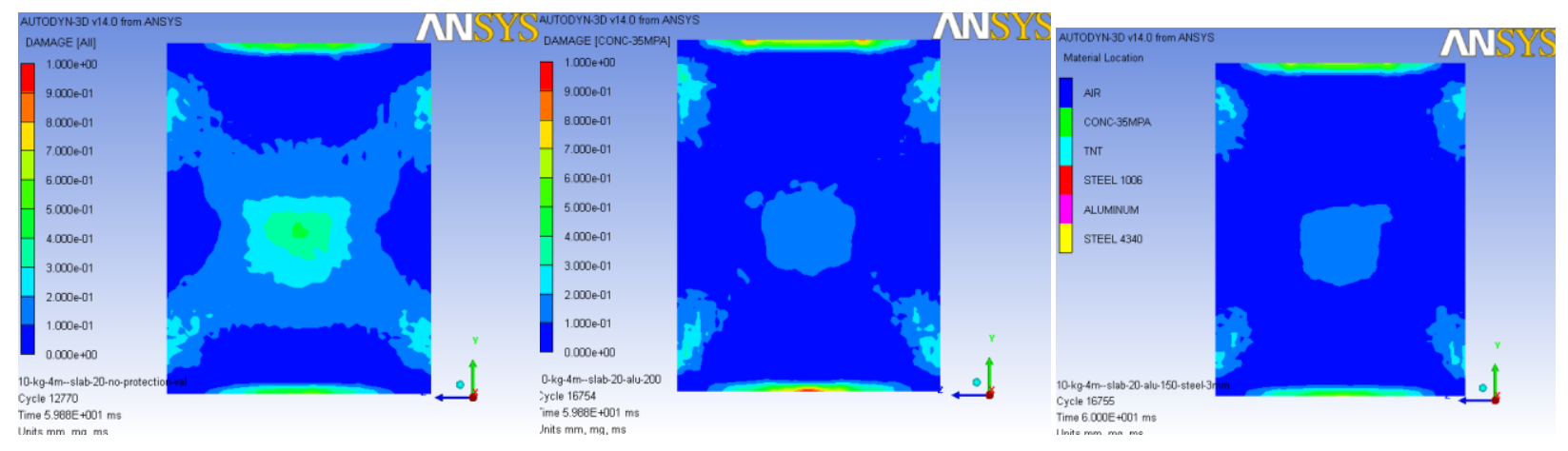

Fig 8. Damage pattern of different case studies for Slab (A) having scaled distance of 1.86

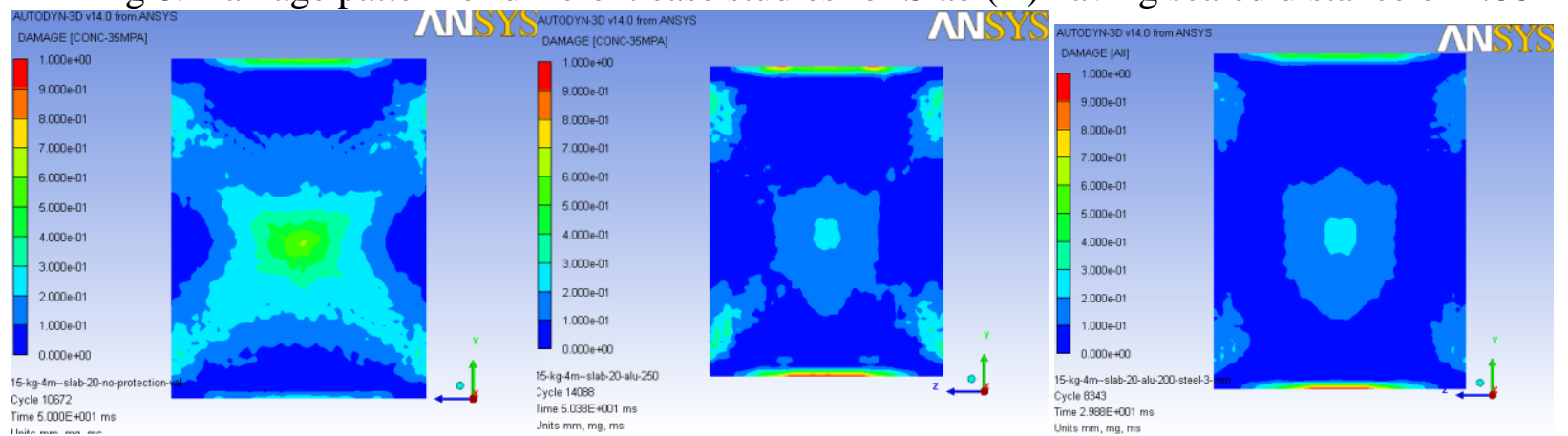

Fig 9. Damage pattern of different case studies for Slab (A) having scaled distance of 1.62
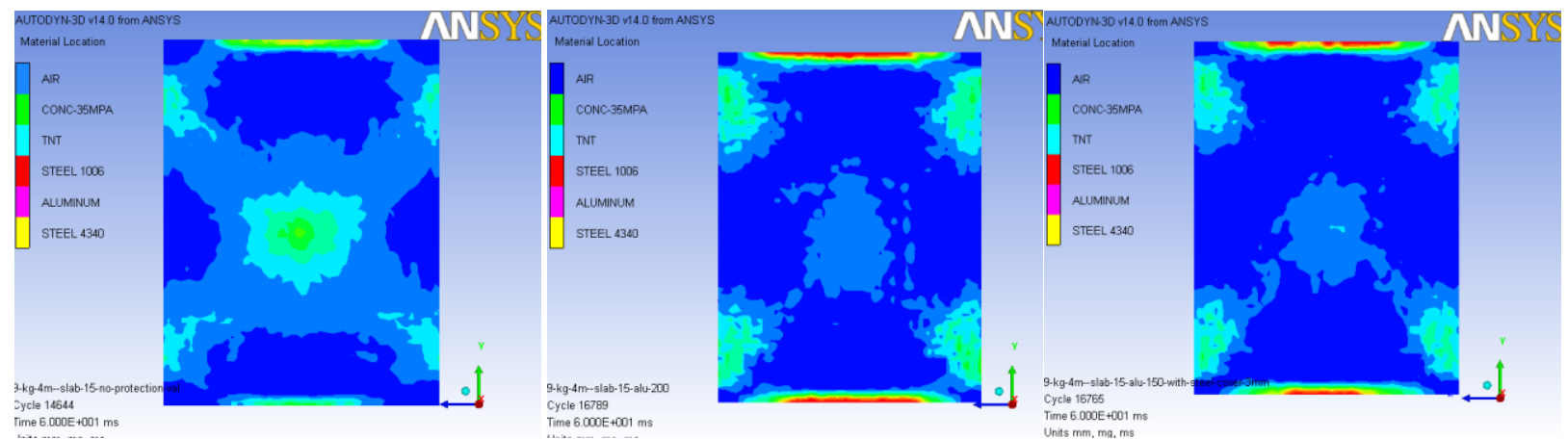

Fig 10. Damage pattern of different case studies for Slab (B) having scaled distance of 1.92

\section{Conclusions}

In this paper, the explosion phenomenon and blast wave propagation in air are numerically simulated and blast wave parameters are calculated using Hydro-codes (AUTODYN-3D).A set of published experimental tests was used to validate the numerical models proposed. In the numerical simulations, RC slab, aluminum foam layer, steel plate, surrounding air, and explosive charge were defined utilizing different Equations of State (EOS) and strength models. Time-dependent results of the response of the protected RC slabs to the blast loads were compared with the corresponding results of the unprotected RC slabs.

The paper led to the following conclusions. The aluminum foam can protect RC slabs and reduces the maximum deflection to its elastic limit. More reduction of the maximum slab deflection can be obtained when using a protection layer composed of steel plate and aluminum foam. Using the steel plate can reduce the thickness of aluminum foam. Steel plate also can increase the stiffness of the RC slab and uniformly distribute the pressure load all over the aluminum foam panel. 
As far as the protection layer composed of aluminum foam and steel plate is concerned, it is clear that it modifies the response of the RC slab. However, a definitive conclusion as to its efficiency for practical purposes requires more tests and analyses.

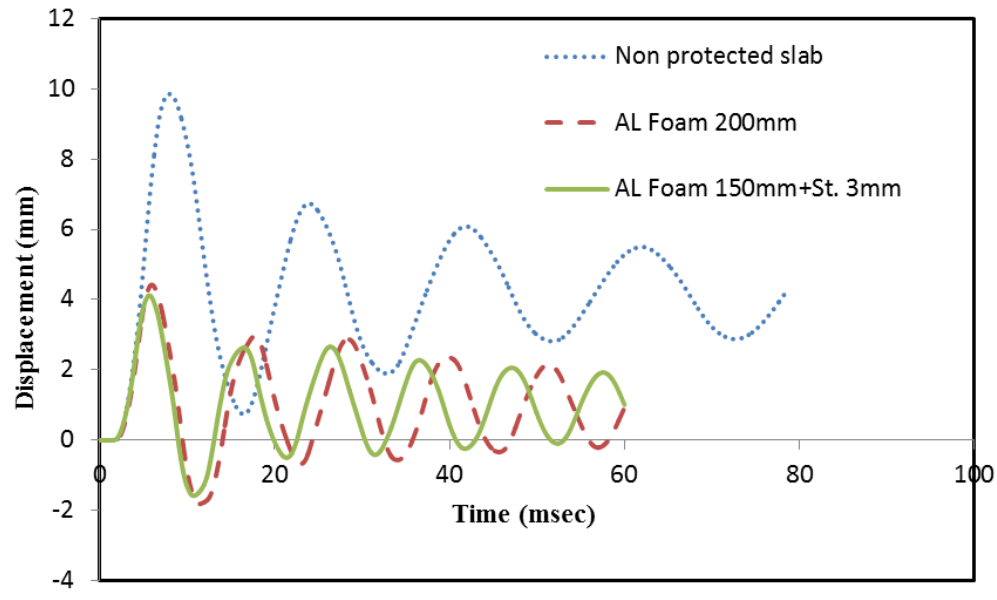

Fig. (11) Displacement-time history of different case studies for Slab A (scaled distance of 1.86)

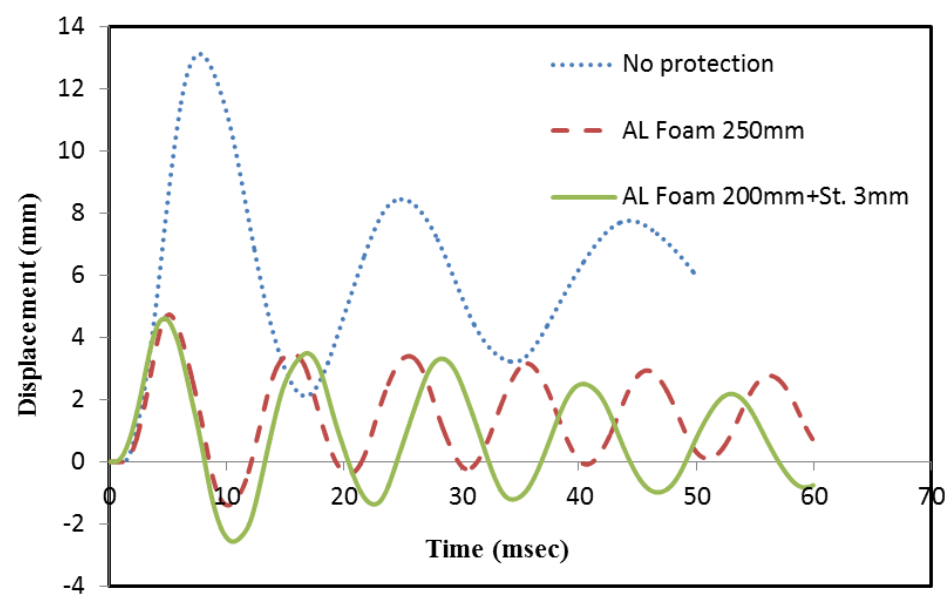

Fig. (12) Displacement-time history of different case studies for Slab A (scaled distance = 1.62)

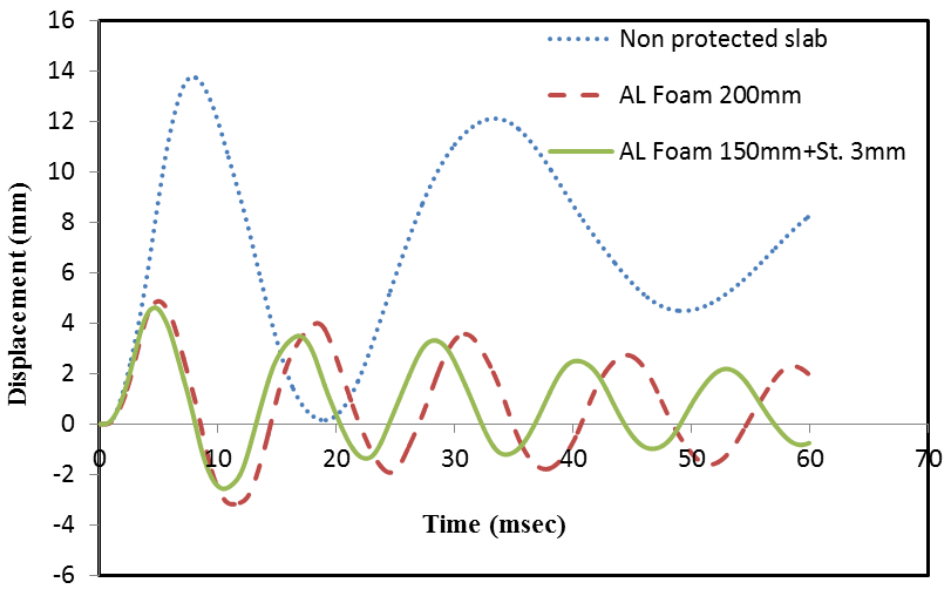

Fig. (13) Displacement-time history of different case studies for Slab B (scaled distance = 1.92) 
Table (3) The parametric Study of different slabs.

\begin{tabular}{|c|c|c|c|c|c|c|}
\hline $\begin{array}{l}\text { Model } \\
\text { no. }\end{array}$ & $\begin{array}{l}\text { Slab thickness } \\
\quad\left(t_{s}\right)(\mathrm{mm})\end{array}$ & $\begin{array}{c}\text { Plate } \\
\text { thickness }\left(t_{p}\right) \\
(\mathbf{m m}) \\
\end{array}$ & $\begin{array}{c}\text { Foam } \\
\text { thickness }\left(t_{f}\right) \\
(\mathbf{m m})\end{array}$ & $\begin{array}{l}\text { Scaled distance } \\
\left(\mathrm{m} / \mathrm{kg}^{1 / 3}\right)\end{array}$ & $\begin{array}{c}\text { Max. } \\
\text { deflection } \\
(\mathrm{mm})\end{array}$ & $\mu$ \\
\hline 1 & 200 & N/A & N/A & 2.34 & 4.3 & 1.00 \\
\hline 2 & 200 & N/A & N/A & 1.86 & 9.7 & 2.26 \\
\hline 3 & 200 & N/A & 50 & 1.86 & 8.5 & 1.97 \\
\hline 4 & 200 & N/A & 100 & 1.86 & 6.7 & 1.56 \\
\hline 5 & 200 & N/A & 150 & 1.86 & 5.4 & 1.25 \\
\hline 6 & 200 & N/A & 200 & 1.86 & 4.2 & 0.97 \\
\hline 7 & 200 & 3 & 150 & 1.86 & 4.09 & 0.95 \\
\hline 8 & 200 & 4 & 100 & 1.86 & 4.77 & 1.10 \\
\hline 9 & 200 & N/A & N/A & 1.62 & 13.1 & 3.05 \\
\hline 10 & 200 & N/A & 150 & 1.62 & 7.44 & 1.73 \\
\hline 11 & 200 & N/A & 200 & 1.62 & 5.93 & 1.38 \\
\hline 12 & 200 & N/A & 250 & 1.62 & 4.65 & 1.07 \\
\hline 13 & 200 & 3 & 150 & 1.62 & 5.52 & 1.28 \\
\hline 14 & 200 & 3 & 200 & 1.62 & 4.51 & 1.03 \\
\hline 15 & 200 & 4 & 150 & 1.62 & 5.16 & 1.20 \\
\hline 16 & 150 & N/A & N/A & 2.77 & 5.2 & 1.00 \\
\hline 17 & 150 & N/A & N/A & 1.92 & 13.8 & 2.65 \\
\hline 18 & 150 & N/A & 100 & 1.92 & 8.57 & 1.65 \\
\hline 19 & 150 & N/A & 150 & 1.92 & 6.45 & 1.20 \\
\hline 20 & 150 & N/A & 200 & 1.92 & 4.8 & 0.92 \\
\hline 21 & 150 & 3 & 100 & 1.92 & 6.09 & 1.17 \\
\hline 22 & 150 & 3 & 150 & 1.92 & 4.56 & 0.87 \\
\hline 23 & 150 & 4 & 100 & 1.92 & 5.67 & 1.09 \\
\hline 24 & 150 & 4 & 75 & 1.92 & 6.56 & 1.26 \\
\hline
\end{tabular}

\section{References}

1. UFC-3-340-02, "Structures to Resist the Effects of Accidental Explosions", Department of Defense, Unified Facilities Criteria, US,. 2008.

2. Razaquur, A.G., Tolba A., and Contestabile E., "Blast loading response of reinforced concrete panels reinforced with externally bonded GFRP laminates". Composites: Part B 38, 2007, pp.535-546. 
3. Tekalur, S.A., Skukla, A., and Shivakumar, K.,, "Blast resistance of polyurea based layered composite materials". Composite Structures 48, 2008, pp. 271-281.

4. Coughlin, A.M., Musselman, E. S., Schokker, A. J., and Linzell, D. G., "Behavior of portable fiber reinforced concrete vehicle barriers subjected to blasts from contact charges". International Journal of Impact Engineering 37, 2010, pp. 521-529.

5. Tabatabaei, Z.S., Volz, J. S., Baird J., Gliha, B. P., and Keener D. I. , "Experimental and numerical analyses of long carbon fiber reinforced concrete panels exposed to blast loading". International Journal of Impact Engineering 57, 2013, pp. 70-80.

6. Ma, G.W., and Ye, Z. Q., "Analysis of foam claddings for blast alleviation,". International Journal of Impact Engineering 34, 2007, pp. 60-70.

7. Hanssen, A.G., Enstock, L., Langseth, M., "Close-range blast loading of aluminium foam panels". International Journal of Impact Engineering 27, 2002, pp. 593-618.

8. $\mathrm{Wu}, \mathrm{C}$., Huang, L., and John D., "Blast testing of aluminum foam-protected reinforced concrete slabs". American Society of Civil Engineers, 2011

9. Chi, Y., Langdon, G. S., Nurick, G., N., "The influence of core height and face plate thickness on the response of honeycomb sandwich panels subjected to blast loading". Materials and Design 31, 2010, pp. 1887-1899.

10. Schenker, A., Anteby, I., Gal, E., Kivity, Y., Eyal, N., Sadot, O., Michaeilis, R., Levintant, O., Ben-Dor, G., "Full scale field tests of concrete slabs subjected to blast loads". International Journal of Impact Engineering 35, 2008, pp. 184-198.

11. AUTODYN theory manual revision 4.3. CENTURY DYNAMICS INC. 2003, California, USA.

12. DOBRATZ, B.M., and CRAWFORD, P.C, LLNL handbook: Properties of chemical explosives and explosive simulants. 1985, California, USA.

13. Herrmann, W., "Constitutive Equation for the Dynamic Compaction of Ductile Porous Materials". Vol. 40. 1969: Journal of App Physics. 2490-2499.

14. $\mathrm{Wu}, \mathrm{C}$., Sheikh, H., "A finite element modelling to investigate the mitigation of blast effects on reinforced concrete panel using foam cladding". International Journal of Impact Engineering 55, 2013, pp. 24-33.

15. Riedel, W., Thoma K., Hiermaier S., Schmolinske E, , "Penetration of Reinforced Concrete by BETA-B-500. Numerical Analysis using a New Macroscopic Concrete Model for Hydrocodes.". Proceedings of 9 th International Symposium on Interaction of the Effects of Munitions with Structures., 1999: p. pp 315-322.

16. Johnson, G.R., Cook W H, "A Constitutive Model and Data for Metals Subjected to Large Strains, High Strain Rates, and High Temperatures". 7th. International Symposium on Ballistics, 1983, pp. 541-547.

17. Kipp, M.E., "Polyurethane Foam Impact Experiments and Simulations," American Physical Socoety, conference on shock compression of Condensed Matter. 1999.

18. Zhu, C., Lin, Z., Chia, Y., Chong, K., "Protection of reinforced concrete structures against blast loading. Final year research project report". Australia: school of Civil, Environmental and Mining Engineering, The university of Adelaide, 2009. 